\title{
Contamination. New developments of a corrective bracing concept resulting from a matching with a different approach
}

\author{
F Tessadri', M Tavernaro, A Zonta, S Negrini \\ From 8th International Conference on Conservative Management of Spinal Deformities and SOSORT 2011 \\ Annual Meeting \\ Barcelona, Spain. 19-21 May 2011
}

\section{Background}

The SPoRT (Symmetric, Patient oriented, Rigid, ThreeDimensional) Sforzesco brace has been developed recently and it is continuously in evolution [1].

PurposePresentation of two new developments to improve the SPoRT concept coming from the Cheneau concept of bracing.

\section{Materials and methods}

The excellent performance of the bottom up action of the SPoRT brace is guaranteed by the drivers, a concept first developed with the Sforzesco brace. Since these cannot be present at the brace's upper and lower margins, it has been hypothesized that the postural action of the Cheneau concept could be used to obtain an increasing of correction. Two innovations (called "Cheneuization" and "open pelvis") has been introduced and tested in a series of cases, with progressive improvement and final selection for application [2]. During the presentation we will discuss a range of clinical cases and carried out experimentations.

\section{Results}

We have introduced two important innovations following one upon the other: the first one relating to the shoulder girdle and the second one relating to the pelvic girdle. In both cases we have obtained a visible translation sustained from the rigidity of the material as well as from the effects of the proper drivers of the SPoRT Brace, according to the aesthetic and appreciably symmetric SPoRT approach.

In particular, the "Cheneausation" relating to the shoulder girdle has obtained creditable results in the

Orthotecnica, Gardolo di Mezzo, Italy

C 2012 Tessadri et al; licensee BioMed Central Ltd. This is an open access article distributed under the terms of the Creative Commons Attribution License (http://creativecommons.org/licenses/by/2.0), which permits unrestricted use, distribution, and reproduction in any medium, provided the original work is properly cited. course of two years of experimentation and has been added to the SPoRT concept. The open pelvis, instead, is still in course of study and development.

Published: 27 January 2012

\section{References}

1. Negrini S, Marchini G, Tessadri F: Brace technology thematic series - The Sforcesco and Sibila braces, and the SpoRT (Symmetric, Patient oriented, Rigid, Three-dimensional, active) concept. Scoliosis 2011, 6:8.

2. Rigo M, Weiss HR: The Cheneau concept of bracing- Biomechanical aspects. Stud Health Technol and Inform 2008, 135:303-319.

doi:10.1186/1748-7161-7-S1-P6

Cite this article as: Tessadri et al:: Contamination. New developments of a corrective bracing concept resulting from a matching with a different approach. Scoliosis 2012 7(Suppl 1):P6.
Submit your next manuscript to BioMed Central and take full advantage of:

- Convenient online submission

- Thorough peer review

- No space constraints or color figure charges

- Immediate publication on acceptance

- Inclusion in PubMed, CAS, Scopus and Google Scholar

- Research which is freely available for redistribution 